\title{
Silibinin attenuates methotrexate-induced pulmonary injury by targeting oxidative stress
}

\author{
SERDAR KALEMCI $^{1}$, YASAR TOPAL ${ }^{2}$, SERKAN YASAR CELIK ${ }^{3}$, NIGAR YILMAZ $^{4}$, HALIL BEYDILLI $^{5}$, \\ MEHMET ILKAY KOSAR ${ }^{6}$, NIGAR DIRICAN ${ }^{7}$ and IRFAN ALTUNTAS ${ }^{4}$ \\ Departments of ${ }^{1}$ Chest Disease,${ }^{2}$ Pediatrics,${ }^{3}$ Pathology, ${ }^{4}$ Biochemistry, ${ }^{5}$ Emergency Medicine and ${ }^{6}$ Anatomy, \\ Medical Faculty, Mugla Sitkı Kocman University, Mugla 48000; ${ }^{7}$ Department of Chest Disease, \\ Medical Faculty, Suleyman Demirel University, Isparta 32000, Turkey
}

Received August 21, 2014; Accepted May 12, 2015

DOI: $10.3892 / \mathrm{etm} .2015 .2542$

\begin{abstract}
The aim of the present study was to assess the protective effect of silibinin against methotrexate (MTX)-induced pulmonary toxicity. Rats were divided into four groups (MTX, MTX + silibinin, silibinin and control. MTX was injected intraperitoneally (i.p) into female Wistar rats $(10 \mathrm{mg} / \mathrm{kg} / \mathrm{day}$ for 3 days), which resulted in significant increases in the serum levels of alanine aminotransferase, aspartate aminotransferase and oxidant enzymes, including nitric oxide and myeloperoxidase. Furthermore, significant reductions were detected in the serum activity levels of the antioxidative enzymes, glutathione peroxidase and superoxide dismutase, when compared with the control group. However, administration of silibinin $(100 \mathrm{mg} / \mathrm{kg} / \mathrm{day}$ for 10 days, i.p.) was shown to ameliorate the MTX-induced pulmonary toxicity, as indicated by the normalization of the oxidative stress parameters. Furthermore, silibinin treatment was demonstrated to reduce the histopathological changes associated with MTX. In conclusion, silibinin exhibited protective effects against MTX-induced pulmonary toxicity, which may be attributed to its antioxidant activity.
\end{abstract}

\section{Introduction}

Methotrexate (MTX) is an antineoplastic agent that is associated with folic acid metabolism. MTX inhibits the synthesis of DNA, RNA, thymidylate and proteins. As a result of this activity, MTX is commonly used in cancer treatment, in addition to the treatment of non-neoplastic diseases, including rheumatoid arthritis and psoriasis (1). Previous studies have demonstrated that liver, kidney, brain and lung toxicities are potential side effects of MTX use (2). The predominant

Correspondence to: Dr Serdar Kalemci, Department of Chest Disease, Medical Faculty, Mugla Sitk1 Kocman University, 4 Orhaniye Street, Mugla 48000, Turkey

E-mail: serdarkalemci@mu.edu.tr

Key words: methotrexate, silibinin, pulmonary toxicity, antioxidant, rat manifestation of MTX-induced lung toxicity is pulmonary fibrosis (3). In addition to pulmonary fibrosis, MTX treatment has been associated with acute interstitial pneumonitis (4-8).

Silibinin $\left(\mathrm{C}_{25} \mathrm{H}_{22} \mathrm{O}_{10}\right.$; molecular weight, $\left.482.44 \mathrm{~g} / \mathrm{mol}\right)$ is isolated from the seeds of Silybum marianum L. (9). The compound is known to exhibit antioxidative activity, which has been previously reported to result in a number of biologically protective effects, including anti-inflammatory, antitumor and hepatoprotective effects (10-13). Silibinin has been demonstrated to be a potent antioxidant, supporting the capacity of cellular antioxidative agents, such as glutathione (GSH) and superoxide dismutase (SOD), to target reactive oxygen species. This activity may partially explain the effectiveness of silibinin in the prevention of hepatic injury, whether this injury is as a result of disease or exposure to toxins, since this antioxidative activity may mitigate the oxidative stress associated with hepatic injury, subsequently preventing the induction of lipid peroxidation (14). Furthermore, silibinin has been widely investigated for anticancer efficacy in a broad range of cancer models. As a consequence of the general anticancer properties associated with flavonoids collectively, there has been significant interest in the possibility of using silibinin as a chemopreventive agent $(11,15)$. Silibinin has been traditionally used in folk medicine, and acute and chronic doses of silibinin administration in animals and humans have resulted in no significant toxicity. However, to the best of our knowledge, an $\mathrm{LD}_{50}$ for silibinin has not been reported in rodent studies. Silibinin intake has been demonstrated to be safe due to its wide usage as a dietary supplement, with sufficient tolerability and minimal toxicity (15). Therefore, the aim of the present study was to assess the possible protective effects of silibinin against MTX-induced pulmonary toxicity in rats.

\section{Materials and methods}

Animals. Animal experiments were approved by the Animal Ethical Committee of Suleyman Demirel University (B.30.2.SDÜ.0.05.06.00-196, 2012; Isparta, Turkey), and the study was conducted in accordance with the National Institutes of Health Guidelines for the Care and Use of Laboratory Animals (8th Edition, 2011). In total, 32 female albino Wistar rats (age, 8-10 weeks) were obtained from the Experimental 
Research Centre of Suleyman Demirel University and housed in an environmentally controlled room at $21 \pm 1^{\circ} \mathrm{C}$ and $75 \pm 5 \%$ humidity, under a 12-h light/dark cycle. The animals were acclimatized for 1 week prior to the study, and had free access to standard laboratory feed and water.

Experimental protocol. Rats were divided into four groups. Since silibinin was solubilized in dimethyl sulfoxide (DMSO), an equal amount of DMSO (10\% v/v) was included in the injections administered to the control group rats. The silibinin group rats received $100 \mathrm{mg} / \mathrm{kg} / \mathrm{day}$ silibinin (Sigma-Aldrich, St. Louis, MO, USA), which was administered via intraperitoneal (i.p.) injection for 10 days (16). The MTX group rats were administered $10 \mathrm{mg} / \mathrm{kg} /$ day MTX (i.p.) on days 7-9, the commercially available form of the drug was used, it was taken from pharmacy with our own means (17). Finally, the MTX + silibinin group rats were cotreated with $100 \mathrm{mg} / \mathrm{kg} /$ day silibinin for 10 days and $10 \mathrm{mg} / \mathrm{kg} / \mathrm{day}$ MTX for 3 days. In all the groups on day 14 , anesthesia was induced by a single i.p. injection of $50 \mathrm{mg} / \mathrm{kg}$ ketamine (Ketalar ${ }^{\circledR}$; Pfizer, Inc., Istanbul, Turkey) and $5 \mathrm{mg} / \mathrm{kg}$ xylasine (Rompun ${ }^{\circledR}$; Bayer, Istanbul, Turkey). Blood samples were collected via cardiac puncture for serum analyses and the lungs were harvested for histological and immunohistochemical analysis.

Biochemical evaluation. All the biochemical analyses were performed in the Department of Biochemistry at Mugla Sitk1 Kocman University (Mugla, Turkey).

Determination of alanine aminotransferase (ALT) and aspartate aminotransferase (AST) activity levels. Serum activity levels of AST and ALT were calculated spectrophotometrically using Beckman Coulter kits and a UniCel DxC 800 Synchron autoanalyzer (Beckman Coulter, Inc., Brea, CA, USA).

Determination of SOD activity. Tissue samples were homogenized at 4,200 x g on ice in 5-10 ml cold buffer [ $20 \mathrm{mM}$ HEPES buffer ( $\mathrm{pH}$ 7.2) containing $1 \mathrm{mM}$ EGTA, $210 \mathrm{mM}$ mannitol and $70 \mathrm{mM}$ sucrose per gram tissue]. Subsequently, the samples were centrifuged at $1,500 \mathrm{xg}$ for $5 \mathrm{~min}$ at $4^{\circ} \mathrm{C}$, and the supernatant was removed. In addition, the blood samples were centrifuged at $2,000 \mathrm{xg}$ for $15 \mathrm{~min}$ at $4^{\circ} \mathrm{C}$, after which the top yellow serum layer was pipetted off, without disturbing the white buffy coat. The serum was diluted 1:5 with sample buffer. The SOD activity was measured in the supernatant and serum using a SOD assay kit (Cayman Chemical Company, Inc., Ann Arbor, MI, USA) with an ELx-800 absorbance reader (Bio-Tek Instruments, Inc., Winooski, VT, USA). The assay was based on the detection of superoxide radicals generated by xanthine oxidase and hypoxanthine. One unit of SOD was defined as the quantity of enzyme required to induce $50 \%$ dismutation of the superoxide radical. The results are expressed in $\mathrm{U} / \mathrm{mg}$ protein tissue for the liver tissue and $\mathrm{U} / \mathrm{ml}$ for the serum.

Determination of glutathione peroxidase (GPX) activity. Tissue samples were homogenized in $5-10 \mathrm{ml}$ cold buffer [50 mM Tris-HCl (pH 7.5), $5 \mathrm{mM}$ EDTA and $1 \mathrm{mM}$ DTT], and centrifuged at $10,000 \mathrm{xg}$ for $15 \mathrm{~min}$ at $4^{\circ} \mathrm{C}$, after which the supernatant was removed. In addition, the blood samples were centrifuged at $700-1,000 \mathrm{xg}$ for $10 \mathrm{~min}$ at $4^{\circ} \mathrm{C}$, and the plasma was removed. GPx activity was measured in the liver tissue and plasma samples using a GPx assay kit (Cayman Chemical Company, Inc.) with an ELx-50 microplate strip washer. GPx activity was measured indirectly by a coupled reaction with glutathione reductase, where the oxidized glutathione was produced upon the reduction of hydroperoxide by GPx.

Determination of nitric oxide (NO) levels. Tissue samples were homogenized in phosphate-buffered saline ( $\mathrm{pH}$ 7.4) and centrifuged at $10,000 \mathrm{x}$ g for $20 \mathrm{~min}$ to isolate the supernatant. A total NO assay was performed via spectrophotometry at $540 \mathrm{~nm}$ using a nitrate/nitrite colorimetric assay kit (Cayman Chemical Company, Inc.) with an ELx-50 microplate strip washer. The assay was based on nitrate and nitrite determinations, in which nitrate and nitrite were the stable end products of the reaction of NO with molecular oxygen. The total accumulation of nitrate and nitrite in the serum and liver tissue samples was evaluated, and expressed in $\mu \mathrm{M} /$ protein.

Determination of myeloperoxidase (MPO) activity. Quantitative detection of MPO activity was conducted using an enzyme-linked immunosorbent assay kit (MPO Instant ELISA; eBioscience, Inc., Vienna, Austria) in an ELx-50 microplate strip washer. The results are expressed in $\mathrm{pg} / \mathrm{ml} /$ protein.

Histopathological analysis of the lung tissue. Histopathological analyses were performed in the Department of Pathology at Mugla Sitk1 Kocman University. Rat lung samples from the different groups were fixed in $10 \%$ neutral buffered formalin for $24 \mathrm{~h}$. After washing with tap water, serial dilutions of alcohol (methyl, ethyl and absolute ethyl) were applied for dehydration. The specimens were cleared in xylene, and embedded in paraffin at $56^{\circ} \mathrm{C}$ in an oven for $24 \mathrm{~h}$. Paraffin bees wax tissue blocks were prepared for sectioning at $5 \mu \mathrm{m}$ thickness using a microtome. Lung tissues were stained with hematoxylin and eosin and observed under a BX46 light microscope (Olympus Corporation, Tokyo, Japan) for histopathological evaluation. Pulmonary damage was evaluated using six parameters, which included interstitial lymphocytic inflammation, interstitial fibrosis, type 2 pneumocyte infiltration, intraalveolar/interstitial macrophage existence, eosinophil existence and granuloma existence (18). Each parameter was scored semiquantitatively with regard to the severity using the following system: 0 (absent), no interstitial lymphocytic inflammation, fibrosis, type 2 pneumocyte infiltration, macrophages, eosinophils or granulomas; 1 (low), limited number of lymphocytes, type 2 pneumocytes, macrophages, eosinophils and granulomas, with minimal fibrosis; 2 (moderate), a variety of features in between a score of 1 and 3; and 3 (severe), diffuse infiltration of an excessive number of lymphocytes, type 2 pneumocytes, macrophages, eosinophils, granulomas and excessive, diffuse fibrosis (6-12).

Statistical analysis. SPSS software, version 21.0 (IBM SPSS, Armonk, NY, USA) and PAST software (http://folk.uio. no/ohammer/past/) were used for data analysis. For comparisons among multiple independent groups one-way analysis of variance (ANOVA) was used. If significance was identified in the test we used the Least Significant Difference (LSD) test for post-hoc analysis. Parametric methods were used 
Table I. Effect of silibinin on the biochemical parameters associated with MTX-induced pulmonary toxicity.

\begin{tabular}{lllllrr}
\hline Group & ALT $(\mathrm{U} / \mathrm{L})$ & AST $(\mathrm{U} / \mathrm{L})$ & SOD $(\mathrm{U} / \mathrm{ml})$ & GPx $(\mathrm{U} / \mathrm{ml})$ & NO $(\mu \mathrm{m} / \mathrm{g})$ & $\mathrm{MPO}(\mathrm{ng} / \mathrm{ml})$ \\
\hline Control & $20.86 \pm 3.34$ & $62.75 \pm 6.24$ & $0.89 \pm 0.14$ & $0.88 \pm 0.14$ & $2.25 \pm 0.36$ & $2.63 \pm 0.76$ \\
Silibinin & $16.25 \pm 2.60$ & $49.38 \pm 7.90$ & $3.54 \pm 0.57$ & $0.24 \pm 0.04$ & $3.05 \pm 0.49$ & $2.70 \pm 0.53$ \\
MTX & $55.38 \pm 8.86^{\mathrm{a}, \mathrm{b}}$ & $86.88 \pm 13.90^{\mathrm{a}, \mathrm{b}}$ & $0.48 \pm 0.08^{\mathrm{a}}$ & $0.19 \pm 0.03^{\mathrm{a}}$ & $4.49 \pm 0.40^{\mathrm{a}}$ & $4.3 \pm 0.56^{\mathrm{a}}$ \\
MTX + silibinin & $31.25 \pm 5.01^{\mathrm{c}}$ & $60.25 \pm 9.64^{\mathrm{c}}$ & $5.40 \pm 0.86^{\mathrm{c}}$ & $0.63 \pm 0.10^{\mathrm{c}}$ & $1.06 \pm 0.17^{\mathrm{c}}$ & $2.33 \pm 0.37^{\mathrm{c}}$
\end{tabular}

Results are presented as the mean \pm standard deviation. ${ }^{\mathrm{a}} \mathrm{P}<0.05$, vs. control group; ${ }^{\mathrm{b}} \mathrm{P}<0.05$, vs. silibinin group; ${ }^{\mathrm{c}} \mathrm{P}<0.05$, vs. MTX group. MTX, methotrexate; ALT, alanine aminotransferase; AST, aspartate aminotransferase; SOD, superoxide dismutase; GPx, glutathione peroxidase; NO, nitric oxide; MPO, myeloperoxidase.

Table II. Histopathological damage parameters detected in the rat pulmonary tissue samples.

\begin{tabular}{|c|c|c|c|c|}
\hline Histopathological parameter & Control & Silibinin & MTX & MTX + silibinin \\
\hline Interstitial lymphocytic inflammation & 0.125 & 0.375 & $1.25^{\mathrm{a}, \mathrm{b}}$ & $0.25^{\mathrm{c}}$ \\
\hline Interstitial fibrosis & 0 & 0 & $0.875^{\mathrm{a}, \mathrm{b}}$ & $0^{\mathrm{c}}$ \\
\hline Type 2 pneumocyte infiltration & 0 & 0 & $0.5^{\mathrm{a}, \mathrm{b}}$ & $0^{\mathrm{c}}$ \\
\hline Intraalveolar/interstitial macrophage existence & 0 & 0.375 & 0.5 & 0.125 \\
\hline Eosinophil existence & 0 & 0.5 & $0.875^{\mathrm{a}}$ & $0.125^{\mathrm{c}}$ \\
\hline Granuloma existence & 0 & 0 & 0.25 & 0 \\
\hline
\end{tabular}

Results are presented as the mean \pm standard deviation. ${ }^{\mathrm{a}} \mathrm{P}<0.05$, vs. control group; ${ }^{\mathrm{b}} \mathrm{P}<0.05$, vs. silibinin group; ${ }^{\mathrm{P}}<0.05$, vs. MTX group. MTX, methotrexate.

for the analysis of the data with a normal distribution, while non-parametric methods were used for the analysis of the variations without a normal distribution. For comparisons among multiple independent groups, ANOVA (Robust test: Brown-Forsythe), one of the parametric methods was used, while for post-hoc analysis, Fisher's LSD test was used. For the comparison of categorical data, Pearson's $\chi^{2}$ test was conducted using the Monte Carlo simulation technique. Quantitative data are expressed as the mean \pm standard deviation, and categorical data are expressed as a number and percentage. Data were analyzed in the $95 \%$ confidence level, where $\mathrm{P}<0.05$ was considered to indicate a statistically significant difference.

\section{Results}

Biochemical analysis. Serum levels of ALT and AST were significantly increased in the MTX group when compared with the control and silibinin groups $(\mathrm{P}<0.05$; Table I). In the MTX + silibinin group, the ALT and AST levels in serum decreased significantly compared with the MTX group $(\mathrm{P}<0.05)$. Furthermore, in the MTX group, the SOD levels decreased significantly when compared with the control group $(\mathrm{P}<0.05)$. The levels of GPx and SOD increased in the MTX + silibinin group when compared with the MTX group, while the MPO values decreased significantly $(\mathrm{P}<0.05)$.

Histopathological alterations. When compared with the control (Fig. 1) and silibinin groups (Fig. 2), the pulmonary damage appeared to be significantly increased in the MTX group (Fig. 3). Similarly, when the MTX + silibinin group was compared with

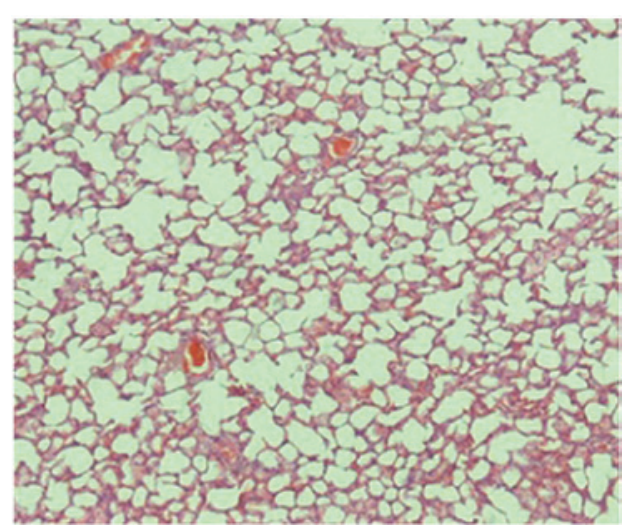

Figure 1. Histological analysis of the control group pulmonary tissue (hematoxylin and eosin; magnification, $\mathrm{x} 40$ ).

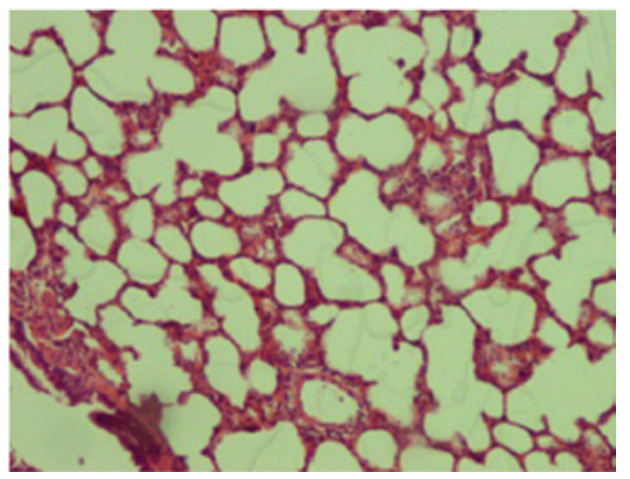

Figure 2. Histological analysis of the silibinin group pulmonary tissue (hematoxylin and eosin; magnification, x100). 

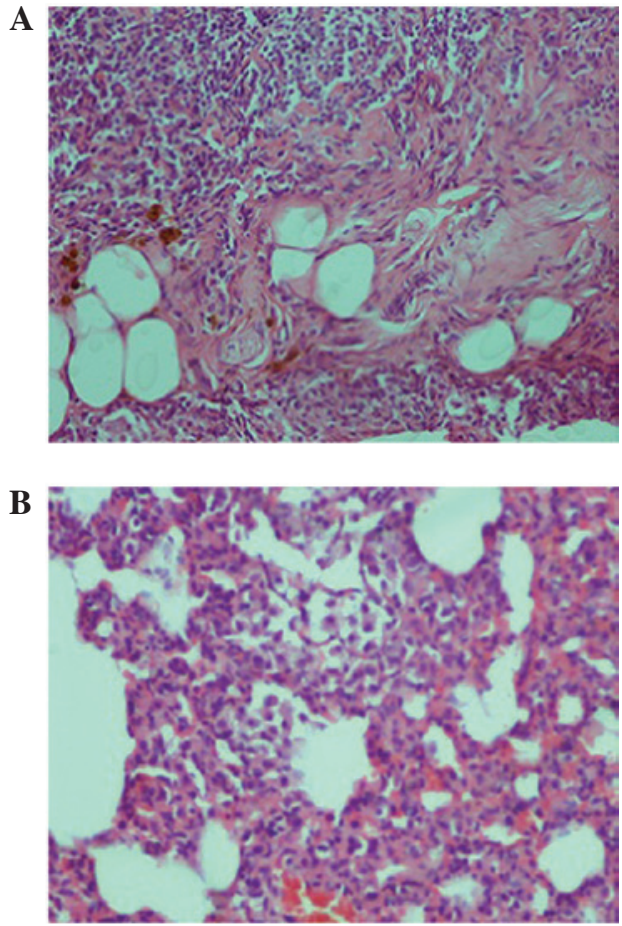

Figure 3. Histological analysis of the methotrexate group pulmonary tissue. (A) Interstitial lymphocytic inflammation and interstitial fibrosis were observed in the pulmonary tissue (hematoxylin and eosin; magnification, $\mathrm{x} 100$ ). (B) Type 2 pneumocyte hyperplasia was also observed in the tissue (magnification, $\mathrm{x} 200$ ).

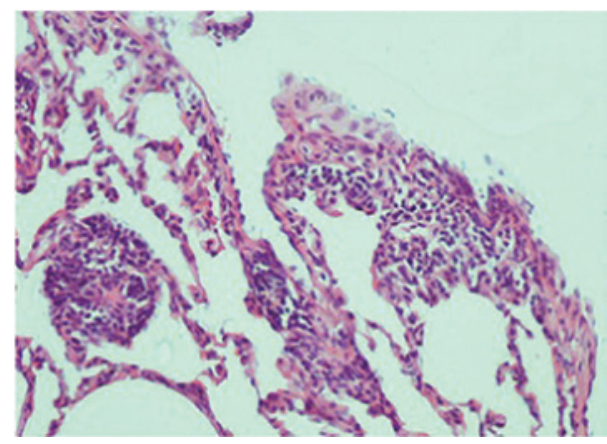

Figure 4. Histological analysis of the methotrexate + silibinin group pulmonary tissue. Slight interstitial lymphocytic inflammation was observed in the pulmonary tissue, in addition to focal type 2 pneumocyte hyperplasia. Interstitial fibrosis was not observed (hematoxylin and eosin; magnification, x200).

the MTX group, the damage was observed to significantly decrease (Fig. 4 and Table II). MTX administration was shown to induce interstitial lymphocytic inflammation, interstitial fibrosis, type 2 pneumocyte hyperplasia and eosinophil infiltration in the pulmonary tissue. However, the MTX + silibinin group exhibited significantly decreased scores for interstitial lymphocytic inflammation, interstitial fibrosis and type 2 pneumocyte hyperplasia when compared with the MTX group, indicating that silibinin exerted beneficial effects (Table II).

\section{Discussion}

The present study evaluated the interactions between silibinin and MTX, and their effects on lung tissue. The results indi- cate that treatment with silibinin ameliorated MTX-induced alterations in the serum ALT and AST levels. In addition, silibinin significantly mitigated the oxidation in the serum induced by MTX, as manifested by the decreased MPO and NO levels, accompanied by enhanced SOD and GPx activity. Furthermore, histopathological analysis demonstrated that administration of silibinin mitigated a number of the histopathological changes induced by MTX.

A previous study indicated that MTX exposure activates components of the mitogen-activated protein kinase (MAPK) signaling pathway (19). Activation of the MAPK and Akt pathways may in turn activate the transcription factors, activator protein- 1 and nuclear factor $-\kappa \mathrm{B}$, which are crucial for the regulation of inflammation (20). Inflammatory cells that infiltrate into the tissue are known to cause tissue damage through activating oxidation systems, such as MPO. Furthermore, inflammatory cells are known to induce cell death by generating DNA damage via oxidation systems (21). In the present study, an increased rate of inflammatory cell infiltration was observed in the pulmonary tissue of the MTX group rats, in addition to elevated oxidation enzyme activity levels (Tables I and II). These observations are consistent with those of previous studies (2).

Silibinin possesses marked antioxidative, anticancer, anti-inflammatory and cancer chemopreventive properties $(22,23)$. Previous studies have reported that silibinin targets multiple signaling pathways, including those associated with oxidative stress and inflammation, to subsequently prevent tissue injuries and cancer by genotoxicity and other agents, which are similar to the pathways triggered following vesicant exposure $(22,24,25)$. Therefore, silibinin was hypothesized to exhibit notable efficacy in attenuating MTX-induced lung injury, since MTX is known to trigger oxidative stress. The results of a previous study by Tewari-Singh et al (21) indicated that vesicant drugs exert a protective effect on the skin, combined with the anti-inflammatory and antioxidative effects of silibinin via the MAPK pathway. In addition, the results of the present study indicated that silibinin administration in combination with MTX decreased the activation of serum oxidation enzyme systems, while increasing antioxidant enzyme levels (Table II). Furthermore, silibinin appeared to reduce inflammatory cell infiltration and MTX-induced changes in the lung tissue (Table II). In accordance with previous literature (14), the current results indicated that silibinin is able to decrease pulmonary oxidative stress, possibly via the MAPK pathway.

The potential for hepatic toxicity remains a concern for physicians who are increasingly using MTX (26). The preventive effect of silibinin against liver damage has been demonstrated in a previous study (10). In the present study, cotreatment with MTX and silibinin was demonstrated to result in significantly decreased serum levels of AST and ALT when compared with MTX treatment alone $(\mathrm{P}<0.05$; Table I). These findings indicate that silibinin decreases MTX-associated tissue damage, which may provide an advantage for clinicians regarding the use of this drug.

In conclusion, silibinin was demonstrated to protect the lung tissue against MTX-induced pulmonary toxicity in rats. The antioxidant activity of silibinin may be the primary factor responsible for such pulmonary protective effects. Therefore, 
silibinin represents a potential candidate agent for the prevention of lung injury, which is a major and dose-limiting side effect of MTX therapy.

\section{Acknowledgements}

The authors thank Mugla Sitkı Kocman University Hospital and School of Medicine.

\section{References}

1. Beckmann-Knopp S, Rietbrock S, Weyhenmeyer R, Böcker RH, Beckurts KT, Lang W, Hunz M and Fuhr U: Inhibitory effects of silibinin on cytochrome P-450 enzymes in human liver microsomes. Pharmacol Toxicol 86: 250-256, 2000.

2. Abelson HT, Fosburg MT, Beardsley GP, Goorin AM, Gorka C, Link $M$ and Link D: Methotrexate-induced renal impairment: Clinical studies and rescue from systemic toxicity with high-dose leucovorin and thymidine. J Clin Oncol 1: 208-216, 1983.

3. Ohbayashi M, Kubota S, Kawase A, Kohyama N, Kobayashi Y and Yamamoto T: Involvement of epithelial-mesenchymal transition in methotrexate-induced pulmonary fibrosis. J Toxicol Sci 39: 319-330, 2014

4. Oktem F, Yilmaz HR, Ozguner F, Olgar S, Ayata A, Uzare E and Uz E: Metothrexate-induced renal oxidative stres in rats: The role of a novel antioxidant caffeic acid phenethyl ester. Toxicol Ind Health 22: 241-247, 2006.

5. Jahovic N, Cevik H, Sehirli AO, Yegen BC and Sener G: Melatonin prevents methotrexate-induced hepatorenal oxidative injury in rats. J Pineal Res 34: 282-287, 2003.

6. Kose E, Sapmaz HI, Sarihan E, Vardi N, Turkoz N and Ekinci N: Beneficial effects of montelukast against methotrexate-induced liver toxicity: A biochemical and histological study. ScientificWorldJournal 2012: 987508, 2012.

7. Ozkan E, Yardimci S, Dulundu E, Topaloğlu U, Sehirli O, Ercan F, Velioglu-Ogunc A and Sener G: Protective potential of montelukast against hepatic ischemia/reperfusion injury in rats. J Surg Res 159: 588-594, 2010

8. Vardi N, Parlakpinar H, Cetin A, Erdogan A and Ozturk IC: Protective effect of carotene on methotrexate-induced oxidative liver damage. Toxicol Pathol 38: 592-597, 2010.

9. Chen PN, Hsieh YS, Chiou HL and Chu SC: Silibinin inhibits cell invasion through inactivation of both PI3K-Akt and MAPK signaling pathways. Chem Biol Interact 156: 141-150, 2005.

10. Schümann J, Prock1 J, Kiemer AK, Vollmar AM, Bang R and Tiegs G: Silibinin protects mice from $\mathrm{T}$ cell-dependent liver injury. J Hepatol 39: 333-340, 2003.

11. Lim R, Morwood CJ, Barker G and Lappas M: Effect of silibinin in reducing inflammatory pathways in in vitro and in vivo model of infection-induced preterm birth. PLoS One 9: e92505, 2014.
12. El Hafny B, Cano N, Piciotti M, Regina A, Scherrmann JM and Roux F: Role of P-glycoprotein in colchicine and vinblastine cellular kinetics in an immortalized rat brain microvessel endothelial cell line. Biochem Pharmacol 53: 1735-1742, 1997.

13. Ting H, Deep G and Agarwal R: Molecular mechanisms of silibinin mediated cancer chemoprevention with major emphasis on prostate cancer. AAPS J 15: 707-716, 2013.

14. Ligeret H, Brault A, Vallerand D, Haddad Y and Haddad PS Antioxidant and mitochondrial protective effects of silibinin in cold preservation-warm reperfusion liver injury. J Ethnopharmacol 115: 507-514, 2008.

15. Mateen S, Raina K and Agarwal R: Chemopreventive and anti-cancer efficacy of silibinin against growth and progression of lung cancer. Nutr Cancer 65 (Suppl 1): 3-11, 2013.

16. Nassuato G, Iemmolo RM, Strazzabosco M, Lirussi F, Deana R, Francesconi MA, Muraca M, Passera D, Fragasso A and Orlando R: Effect of Silibinin on biliary lipid composition. Experimental and clinical study. J Hepatol 12: 290-295, 1991.

17. Sekeroğlu ZA and Sekeroğlu V: Effects of Viscum album L. extract and quercetin on methotrexate-induced cyto-genotoxicity in mouse bone-marrow cells. Mutat Res 746: 56-59, 2012.

18. Imokawa S, Colby TV, Leslie KO and Helmers RA: Methotrexate pneumonitis: Review of the literature and histopathological findings in nine patients. Eur Respir J 15: 373-381, 2000.

19. Kim YJ, Song M and Ryu JC: Inflammation in methotrexate-induced pulmonary toxicity occurs via the p38 MAPK pathway. Toxicology 256: 183-190, 2009.

20. Pal A, Tewari-Singh N, Gu M, Agarwal C, Huang J, Day BJ, White CW and Agarwal R: Sulfur mustard analog induces oxidative stress and activates signaling cascades in the skin of SKH-1 hairless mice. Free Radic Biol Med 47: 1640-1651, 2009.

21. Tewari-Singh N, Jain AK, Inturi S, Agarwal C, White CW and Agarwal R: Silibinin attenuates sulfur mustard analog-induced skin injury by targeting multiple pathways connecting oxidative stress and inflammation. PLoS One 7: e46149, 2012.

22. Singh RP and Agarwal R: Mechanisms and preclinical efficacy of silibinin in preventing skin cancer. Eur J Cancer 41: 1969-1979, 2005.

23. Deep G and Agarwal R: Antimetastatic efficacy of silibinin: Molecular mechanisms and therapeutic potential against cancer. Cancer Metastasis Rev 29: 447-463, 2010.

24. Dhanalakshmi S, Agarwal C, Singh RP and Agarwal R: Silibinin up-regulates DNA-protein kinase dependent p53 activation to enhance UVB-induced apoptosis in mouse epithelial JB6 cells. J Biol Chem 280: 20375-20383, 2005.

25. Mallikarjuna G, Dhanalakshmi S, Singh RP, Agarwal C and Agarwal R: Silibinin protects against photocarcinogenesis via modulation of cell cycle regulators, mitogen-activated protein kinases and Akt signaling. Cancer Res 64: 6349-6356, 2004.

26. Hassan W: Methotrexate and liver toxicity: Role of surveillance liver biopsy. Conflict between guidelines for rheumatologists and dermatologists. Ann Rheum Dis 55: 273-275, 1996. 